\title{
The known distribution and ecological preferences of the tick subgenus Boophilus (Acari: Ixodidae) in Africa and Latin America
}

\author{
A. ESTRADA-PEÑA ${ }^{1, *}$, A. BOUATTOUR ${ }^{2}$, J.-L. CAMICAS ${ }^{3}$, \\ A. GUGLIELMONE ${ }^{4}$, I. HORAK ${ }^{5}$, F. JONGEJAN ${ }^{5,6}$, A. LATIF $^{7}$, \\ R. PEGRAM ${ }^{8}$ and A.R. WALKER ${ }^{9}$ \\ ${ }^{1}$ Department of Parasitology, Faculty of Veterinary Medicine, Miguel Servet, 177, 50013-Zaragoza, \\ Spain; ${ }^{2}$ Institut Pasteur, Tunis, Tunisia; ${ }^{3}$ Laboratoire d'Acarologie Médicale, Centre IRD, Mont- \\ pellier, France; ${ }^{4}$ INTA, Rafaela, Argentina, ${ }^{5}$ Department of Veterinary Tropical Diseases, Faculty of \\ Veterinary Science, University of Pretoria, Onderstepoort 0110, South Africa, ${ }^{6}$ Faculty of Veterinary \\ Medicine, Utrecht University, P.O. box 80.165, 3508 TD Utrecht, The Netherlands; ${ }^{7}$ Onderstepoort \\ Veterinary Institute, ARC, Onderstepoort, South Africa, ${ }^{8}$ FAO Caribbean Amblyomma Program. \\ Friars Hill Road. P.O. Box 1572, Woods Centre, St. Johns, Antiqua; ${ }^{9}$ Centre for Tropical Veterinary \\ Medicine, University of Edinburgh, Scotland, UK; \\ *Author for correspondence (e-mail: aestrada@unizar.es)
}

Received 16 June 2005; accepted in revised form 23 January 2006

Key words: Boophilus, Distribution, Ecological preferences, Populations

\begin{abstract}
A compilation of the known distribution of Boophilus ticks in Africa and Latin America is presented, together with details on climate preferences. B. annulatus is recorded mainly in the western part of a strip from the equator to parallel $20^{\circ} \mathrm{N}$. It associates with woodlands and forests (lowland rain forest and secondary grassland). This species is also present in the Mediterranean region, associated to woodland and open areas. B. decoloratus extends southern to parallel $20^{\circ} \mathrm{N}$, in woodland with montane vegetation and Zambezian miombo; some records have been collected in the highveld grassland. B. geigyi is mainly collected in the western range of a stripe extending between parallels $5^{\circ} \mathrm{N}$ and $18^{\circ} \mathrm{N}$, associated with Sudanian woodland, lowland rain forest with secondary grassland and woodland. Confirmed records of microplus in Africa are restricted to Malagasy region and south and eastern Africa, being predominant in the Zambezian miombo, deciduous forest with secondary grassland, and woodland. In Latin America, microplus is abundant in the Mesoamerican corridor to Venezuela and Colombia, and southern in Brazil and Argentina. The tick is mainly associated to the biomes of Chaco and Pampas in Argentina, the North-central moist Andes, the Atlantic forest (southern range) and the moist Meso-American vegetation (northern range). Most collections of $B$. annulatus and $B$. geigyi came from areas where winter minimum temperature is above $15^{\circ} \mathrm{C}$, maximum temperatures remain between 33 and $36^{\circ} \mathrm{C}$ and maximum rainfall is recorded between June and September. $B$. decoloratus and African $B$. microplus are recorded in sites with low temperatures in May-September. Minimum temperature requirements are similar for both $B$. decoloratus and African B. microplus, and both are around $4{ }^{\circ} \mathrm{C}$ less than the value recorded for collections of Latin-American B. microplus. The rainfall pattern observed for decoloratus shows a minimum in May and June. The requirements of total rainfall are highest for B. microplus in Latin America, while records of African B. microplus are concentrated in areas of low rainfall between May and October, and high rainfall between November and March (low rainfall in the same period for B. decoloratus). Statistical analysis revealed the existence of populations (demes) with ecologically different requirements within each tick species. Both $B$. annulatus and $B$. decoloratus showed many different demes clearly associated
\end{abstract}


to defined areas. The collections of Latin American B. microplus are very homogeneous according climate preferences and well separated from the African counterpart.

\section{Introduction}

Boophilids are some of the most important tick species in the world from an economical point of view. Each of the five Boophilus species has a one-host life cycle that may be completed in 3-4 weeks and results in heavy tick burden (Walker et al. 2003). B. microplus, considered the most important parasite of livestock in the world, has been introduced from the bovid- and cervidinhabited forests of the Indian region to many areas of tropical and subtropical Asia, northeastern Australia, Madagascar, coastal lowlands of southeastern Africa to the equator, and much of South and Central America, Mexico and the Caribbean. B. annulatus, original from the former southern USSR, the Near and Middle East, and the Mediterranean area, was introduced with livestock of the early Spanish colonialists into northeastern Mexico but has not spread into Central America. B. microplus and B. annulatus were eradicated from the USA after a long, costly control program, and constant surveillance is maintained to prevent its reintroduction (George 1987). B. decoloratus, which ranges from southern Africa to the Sahara, is being replaced in the eastern and southeastern part of this area by B. microplus. This seems to be caused by the shorter life cycle of microplus, as well as the tendency to assortative mating and more successful feeding on cattle and is cause of much concern in the area, because the expansion of microplus-transmitted pathogens (Tonnesen et al. 2004). In more humid West African zones, B. annulatus mixes with or is totally replaced by $B$. geigyi. However, no competition has been reported between these species, as little is known from the life cycle of B. geigyi. B. annulatus further extends into eastern Africa, as a line southern to the limits of Sahara desert. The only boophilid restricted to sheep and goats (and occasionally horses) is B. kohlsi of Syria, Iraq, Israel, Jordan, western Saudi Arabia, and the Yemen. Boophilus microplus is an experimental vector of Theileria equi, and this tick and B. annulatus are major vectors of Babesia bigemina, Babesia bovis, and Anaplasma marginale. B. decoloratus is an efficient vector of B. bigemina and $A$. marginale but does not transmit $B$. bovis. This tick apparently does not transmit $T$. equi, but it is an experimental vector of $A$. marginale to cattle. Recent studies of the taxonomy of the group, using molecular taxonomy methodologies, have proposed a radical change placing the five species in the genus Boophilus in the genus Rhipicephalus (Murrell et al. 2000; Beati and Keirans 2001). Horak et al. (2002) proposed to Boophilus as a subgeneric epithet. Throughout this paper, however, Boophilus will be used as not final decision about the taxonomic status of these five species has been officially approved. It should be noted that this does not imply a position about the systematics of the boophilids, but only a way to refer to the ticks included in this study.

Ecological niches delineate the set of conditions under which species can maintain populations in the long-term. Individuals living outside the niche 
conditions do not replace themselves. There is a wide theoretical treatment of the features of the ecological niche (Holt 1996; Holt and Gomulkiewicz 1996) that clarifies the relationships between ecological niche, geographic distributions and evolutionary dynamics. These studies suggest that, in general, longterm natural selection pressures will maintain the ecological niche without substantial modification. This reasoning supports the idea that species ecological niche represents long-term stable constraints on geographic distributional potential. The fundamental niche can be viewed as the set of conditions and resources that allow a given organism to survive and reproduce in the absence of biotic interactions. An understanding of the fundamental niche can provide us with greater insight into the causes of distribution and abundance. This is a solid foundation for exploring the role of biotic interactions and to extrapolate with greater confidence the adaptation to novel circumstances such as climate change and species introductions. We present in this study data about the known distribution of Boophilus ticks in Africa and Latin America. Populations of ticks of the same species are detected, as groups of ticks supporting different climate conditions. An overview of the climate preferences as calculated among the statistically detected populations of ticks is also presented, as a mechanistic approach to study the climatic component as driving force of the distributions of ticks in the subgenus.

\section{Material and methods}

The basis for the current study has been the huge compilation of data on the distribution of ticks in Africa, Latin America and the Caribbean performed by the authors (ICTTD 2004). In that preliminary study, published records from ticks as well as data from collections in scientific institutions were compiled, edited by local experts, and mapped to latitude and longitude coordinates. Data from a previous compilation by Cumming (1999) have been also edited to remove inaccurate references or misdeterminations, and added to the database. The compilation on which this paper is based is thus the largest database on the recorded distribution of Boophilus ticks. Some data have not been used, as follows. B. kohlsi was not included in the original compilation because its importance for domestic animals is unknown (Walker et al. 2003). Our current knowledge about the distribution of Boophilus ticks in areas of Asia is still fragmentary. This study is intended to provide a complete review in the areas were these ticks are present, so it has been considered better to not incorporate the records from Asia. Data on B. microplus in Australia are selective for the area known to be infested and we lack adequate references (geographical data) to collection sites. Therefore, only records from Africa and the Neotropics have been included. Records from B. annulatus in the Americas have been also omitted, as the presence of this taxon in the region is scattered. Furthermore, early records from both $B$. microplus and $B$. annulatus in USA have been avoided, as it is difficult to ascribed these records to the climate at the time they 
were collected. For the whole study, records lacking an adequate geographical reference were not included.

This database of tick records has been checked against a spatially and temporally extensive gridded climate data set that extends between 1950 and 1999. The data set of world climate was built by New et al. (1999) and was developed by interpolating observations taken at meteorological stations, corrected with the altitude. This is a gridded data set that contains monthly records of temperature (mean, minimum and maximum) and precipitation (monthly total) at a resolution of $10 \mathrm{~km}$. Other than these basic monthly variables, we compiled a further set of 19 variables that are herein called yearly variables. Those explain much of the variability in the year, and contribute to further homogenize observations. The yearly variables are 1: Annual Mean Temperature, 2: Mean Diurnal Range (Mean of monthly (max temp - min temp)), 3: Isothermality $(2 / 7 * 100), 4$ : Temperature Seasonality (standard deviation * 100), 5: Max Temperature of Warmest Month, 6: Min Temperature of Coldest Month, 7: Temperature Annual Range (5-6), 8: Mean Temperature of Wettest Quarter, 9: Mean Temperature of Driest Quarter, 10: Mean Temperature of Warmest Quarter, 11: Mean Temperature of Coldest Quarter, 12: Annual Precipitation, 13: Precipitation of Wettest Month, 14: Precipitation of Driest Month, 15: Precipitation Seasonality (Coefficient of Variation), 16: Precipitation of Wettest Quarter, 17: Precipitation of Driest Quarter, 18: Precipitation of Warmest Quarter, 19: Precipitation of Coldest Quarter.

We extracted both monthly and yearly variables for each tick record. Care was taken to associate each tick record with the climate at the time the collection was done, using the averaged climate values of the year of capture (as included in the tick database) and the 5 previous years. This procedure provided every tick record with the climate to which it has been associated and avoided the bias derived from the connection of the tick record with uncommon climate values. No attempts were done to obtain also climate features from sites where no data on Boophilus ticks was available to compare with climate values for ticks records. The mapping of ticks as absent in sites where only other species were collected may introduce a potentially dangerous bias in the actual distribution of a species. For each tick species, we obtained the range of values (mean $\pm \mathrm{SD}$ ) for every monthly and yearly variable.

The complete set of records for each species was separated in demes, representing populations of ticks within the same species collected in statistically different ecologically zones. This part of the study is intended to know if populations with statistically different climate preferences exist in diverse geographic areas and to understand the ecological niche relationships within demes of each species. This point has major implications in predictive mapping, as projecting algorithms are commonly evaluated over populations covering relatively large areas. It has been already demonstrated that habitat classification (presence/absence) accuracy for Glossina spp. became further accurate by subdividing the habitat into ecological zones prior to performing discriminant analysis (Robinson 1998). However, we cannot use only climate to sub- 
divide the habitat into significantly different zones, as the climate conditions under which the ticks have been collected would be correlated with these climatically different regions. The subdivision of the area into statistically different zones based solely on climate would provide automatically different tick populations. For this purpose, we selected a set of remotely sensed images with monthly information of Normalized Derived Vegetation Index (NDVI, which is linearly uncorrelated with climate) and performed an unsupervised classification of the habitat in Africa (including the Mediterranean part) and Latin America. The procedure provided with an assemblage of NDVI-based habitat categories, whose NDVI value are statistically homogeneous within each category, and different for zones between separate categories. Records of each species as collected into each vegetation category were initially treated as separate demes. A cluster analysis was performed in using the climate data associated to every tick record to understand the relationships of the species as clusters in the $n$-dimensional space of the climate variables. To avoid bias in the estimation, vegetation categories representing less than $5 \%$ of the captures of the species were avoided in further analysis. This procedure allows a direct comparison of the climate requirements by the strict definition of the space of variables as requirements or each species. Special attention was paid to $B$. decoloratus and the African records of $B$. microplus. The spread of $B$. microplus in Africa has been already reported for some parts of the continent, replacing $B$. decoloratus in parts where the climate is suitable for the invader (Tonnesen et al. 2004). This procedure will provide with information about the ecological space occupied by both species, and the degree of ecological plasticity of B. microplus in Africa.

\section{Results}

Figures 1 to 3 display the zones where boophilid ticks have been collected, with information about the vegetation categories separated according NDVI. $B$. annulatus is present in a relatively wide strip extending from the equator to parallel $20^{\circ} \mathrm{N}$, being predominant in the western part of this stripe (Figure 1a). The species is also present north of the Sahara, with most collections in Morocco and Tunisia, and scattered in zones of Egypt, Libya and Algeria. It associates with two main types of vegetation dynamics, namely one which remains at low NDVI values for much of the year (Mediterranean region and first zone south of Sahara desert) and one with clear increase in NDVI after July-August, coinciding with the rainy season. The species has been collected as associated mainly with woodlands (Sudanian and undifferentiated woodland) and forests (lowland rain forest and secondary grassland). B. decoloratus extends into much of Africa, southern to parallel $20^{\circ} \mathrm{N}$ with some isolated records northern to Sahara. These records appear to be accidental importations. It is associated with several vegetation categories, all of them but two being characterized by a prominent decrease of NDVI values between May and 

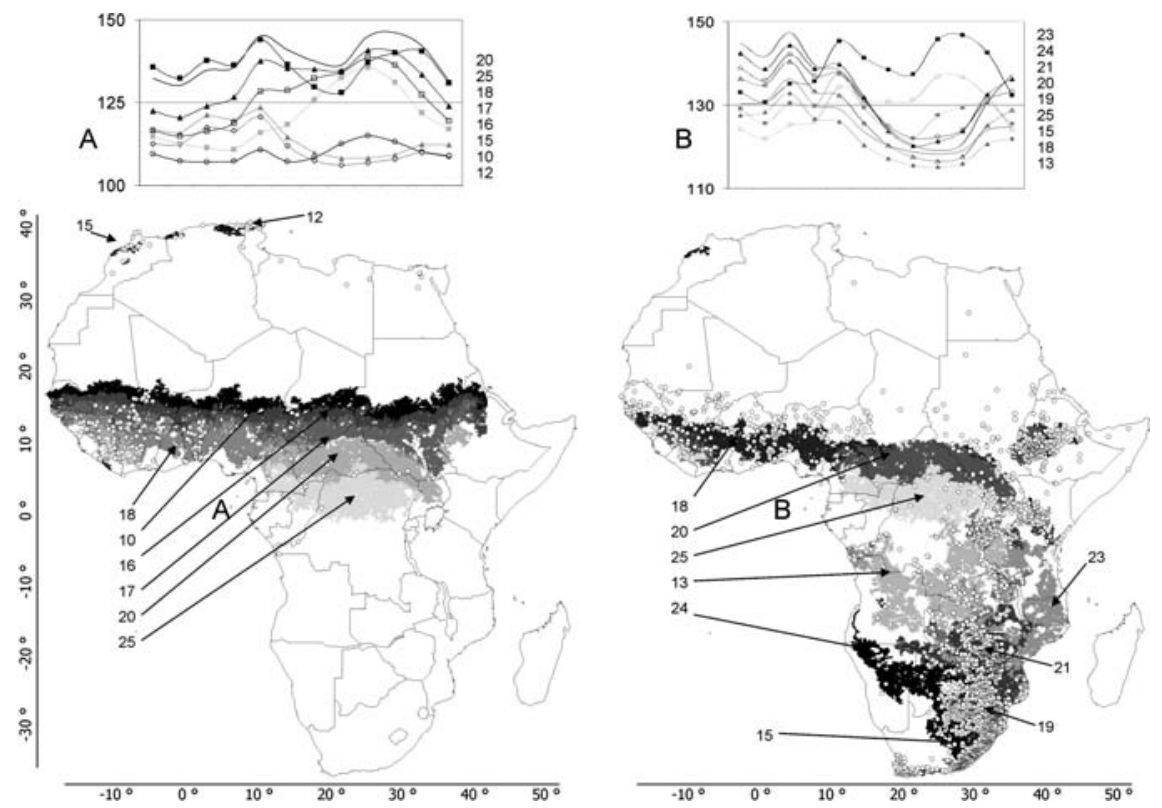

Figure 1. Distribution range of B. annulatus (a) and B. decoloratus (b) in Africa. Dots show the confirmed records of these ticks. Areas in different shades of grey are the statistically different vegetation areas (according to monthly NDVI values) determined by unsupervised classification, to which records of ticks are associated. Areas where less than $5 \%$ of tick records of each species have been collected are not shown. Maps include reference to Latitude and Longitude (bars below and lateral). Upper to each map is a chart with the monthly profile of NDVI values for each vegetation zone, in a range from 0 to 256 . Each number as associated with areas in the map and charts are the vegetation classes as recorded by unsupervised classification of NDVI values.

September and then an increase in the last part of the year. The two remaining regions, located at the northern portion of its distribution range (arrows in Figure 1b), are characterized by high values of NDVI, with an increase after September. $B$. decoloratus has been collected associated to a variety of biomes. It is a tick of woodland, mainly undifferentiated woodland with montane vegetation and Zambezian miombo. Some records have been collected in the highveld grassland. B. geigyi is mainly collected in the western range of a narrow stripe extending between parallels $5^{\circ} \mathrm{N}$ and $18^{\circ} \mathrm{N}$, although the vegetation zones where the tick has been found extend well into eastern Africa. All these categories of vegetation are characterized by relatively high NDVI values with a small decrease in July-August. The exceptions are the zones in the northern range of distribution (mainly in central Mali) where NDVI values are low in the first months of the year. The species is mainly associated to Sudanian woodland, lowland rain forest with secondary grassland and undifferentiated woodland. A significant proportion of captures has been collected associated to wetter types of lowland forests. Confirmed records of B. microplus in Africa are restricted to Malagasy region and south-eastern Africa, in areas mainly 

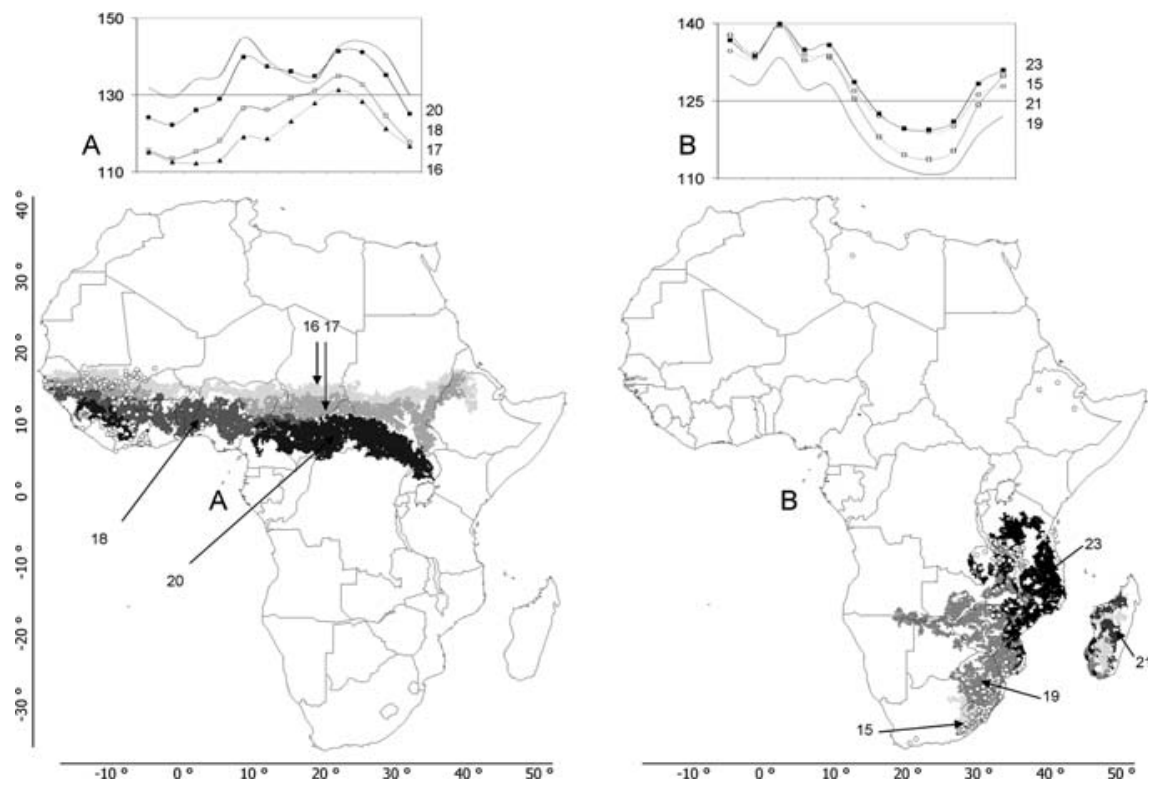

Figure 2. Distribution range of B. geigyi (a) and B. microplus (b) in Africa. Dots show the confirmed records of these ticks. Areas in different shades of grey are the statistically different vegetation areas (according to monthly NDVI values) determined by unsupervised classification, to which records of ticks are associated. Areas where less than 5\% of tick records of each species have been collected are not shown. Maps include reference to Latitude and Longitude (bars below and lateral). Upper to each map is a chart with the monthly profile of NDVI values for each vegetation zone, in a range from 0 to 256 . Each number as associated with areas in the map and charts are the vegetation classes as recorded by unsupervised classification of NDVI values.

characterized by very low NDVI values between July and October, coincident with a dry season (see below) while keeping high the rest of the year. While the vegetation zones where $B$. microplus has been found in Africa are easily characterized by NDVI values, they fall within a wide range of biomes, the tick being predominant in the Zambezian miombo, the mosaic of dry deciduous forest with secondary grassland, and the undifferentiated woodland. In Latin America, B. microplus has a bipolar distribution, being abundant in the Mesoamerican corridor to Venezuela and Colombia, and southern in Brazil and Argentina. Scatter records occur in the Amazonian region, probably as result of importations. B. microplus occupies two types of vegetative areas according to NDVI values: the first is located in the northern portion of its distribution range, and characterized by relatively high, slightly variable NDVI values through the year, while the second is located in its southern distribution range, and characterized by very high NDVI values with a sharp decrease in midwinter (August-October). The tick is mainly associated to the biomes of Chaco and Pampas regions in Argentina, together with the North-central moist Andes, and the Atlantic forest (southern range) and the moist Meso-American vegetation (northern range). 


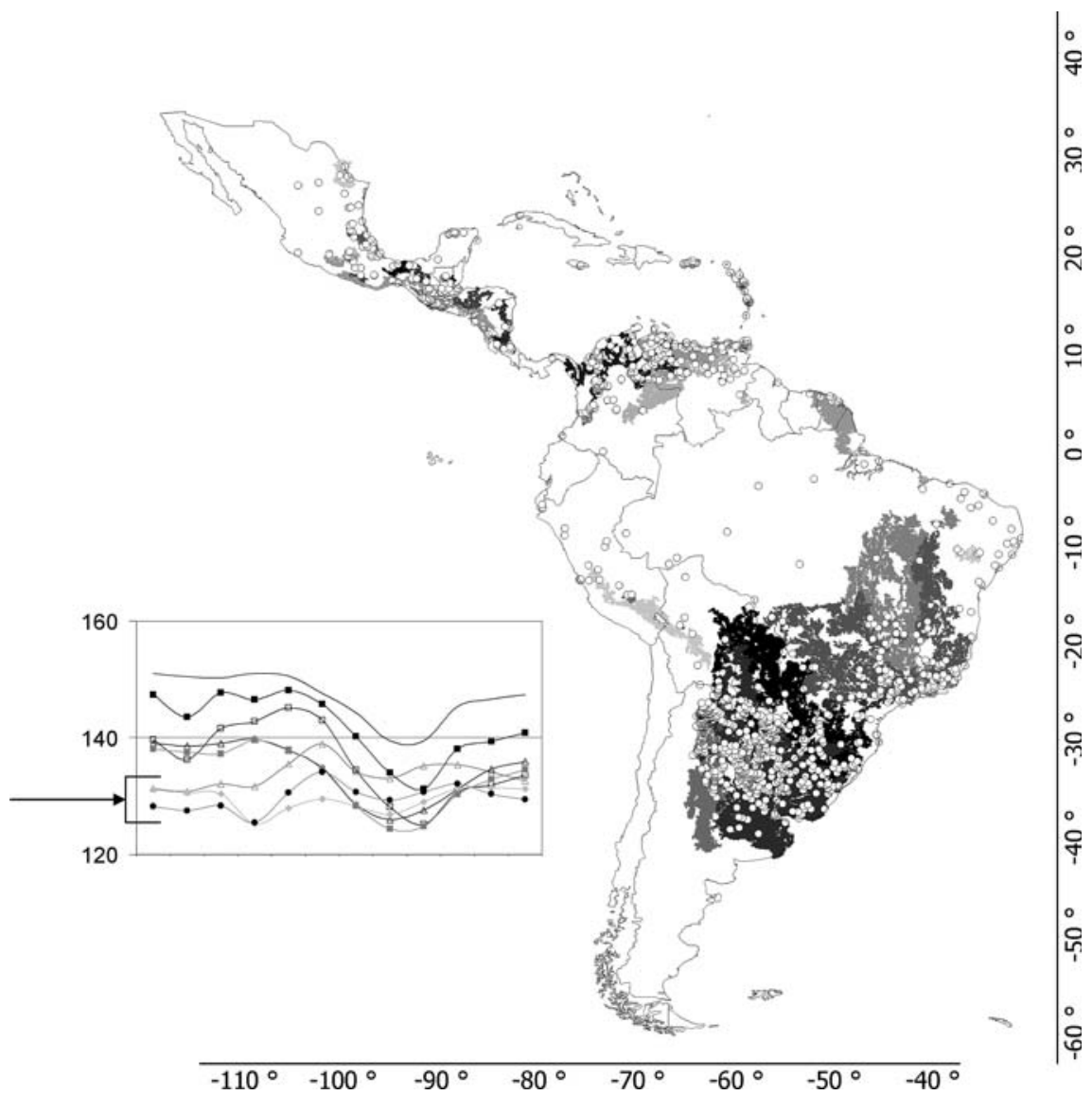

Figure 3. Distribution range of B. microplus in Latin America. Dots show the confirmed records of these ticks. The tick is present in many parts of the Caribbean, but adequate coordinates to these records are lacking. Areas in different shades of grey are the statistically different vegetation areas (according to monthly NDVI values) determined by unsupervised classification, to which records of ticks are associated. Areas where less than 5\% of tick records of each species have been collected are not shown. Map includes reference to Latitude and Longitude (bars below and lateral). Upper to the map is a chart with the monthly profile of NDVI values for each pictured vegetation zone, in a range from 0 to 256 . Arrows in chart point to the monthly NDVI pattern observed for the Meso-American corridor. The other lines correspond to the different areas in the southern distribution range.

Figure 4 shows the averaged monthly and yearly climate variables as recorded in the sites of tick collections. Both B. annulatus and B. geigyi are the species with preferences towards high temperatures. They have been mainly collected in areas were winter minimum temperature is above $15^{\circ} \mathrm{C}$. They prefer zones where maximum temperatures remain between 33 and $36^{\circ} \mathrm{C}$. The requirements for temperatures are always higher for $B$. geigyi than for B. annulatus. Both species have been collected in areas were maximum rainfall 

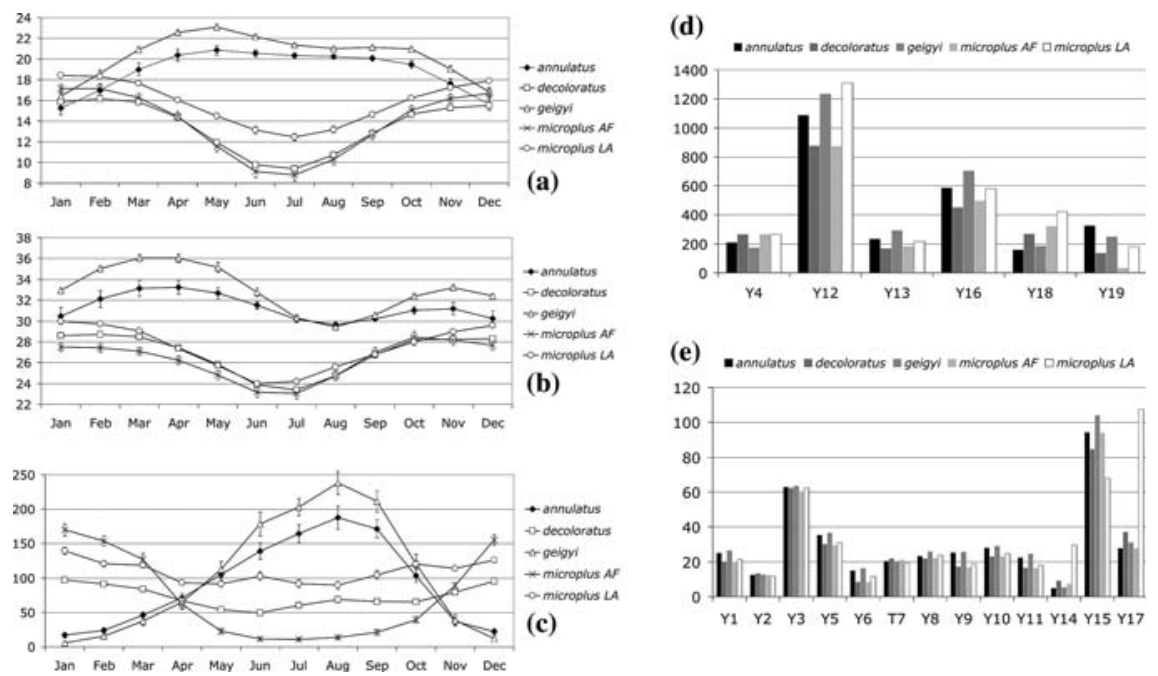

Figure 4. Mean monthly (a, b, c,) and yearly (d, e) values of climate variables recorded for the known collections of $B$. annulatus, B. decoloratus, B. geigyi and B. microplus (in both Latin America, LA, and Africa, AF). Figure 4a shows the mean minimum monthly temperatures recorded for collection points of the species, (b) the mean maximum temperatures, and (c) the mean monthly rainfall. Bars represent SD. Figures $4 d$ and e display the yearly variables (Y) with a number according the list of variables in Material and Methods.

is recorded between June and September (Figure 4c). Populations of these two species support a period of low rainfall when temperatures are maximum. Both species have high requirements of annual precipitation, precipitation of wettest month and precipitation of wettest quarter (Y12, Y13 and Y16, respectively, higher for geigyi), while supporting the smallest values for the precipitation of the warmest quarter (Y18). It is interesting to compare the temperature preferences of both decoloratus and African microplus. While summer temperature requirements are higher for microplus, recorded values for winter are slightly lower than those observed for decoloratus. Minimum monthly temperatures are similar for B. decoloratus and the African populations of B. microplus, and both are around $4{ }^{\circ} \mathrm{C}$ less than the mean recorded for sites of collections of B. microplus in Latin America. The rainfall outline observed for decoloratus shows a pattern of low rainfall regimes, with minimum in May and June. The requirements of rainfall for microplus in Latin America are higher, while African microplus are concentrated in areas of very low rainfall between May and October, and high rainfall between November and March. The periods of high rainfall in African microplus coincides with the periods of maximum temperatures supported by these populations. Although African populations of microplus have requirements of high total rainfall, they can support long periods of dryness in winter. Figures $2 \mathrm{~d}$ and e include the average values observed for the yearly variables. Critical differences can be observed in the precipitation of driest month, precipitation seasonality and precipitation of 
driest quarter (Y14, Y15 and Y17) as related with American microplus records, for which precipitation seasonality is smaller than for other species and the total rainfall in the driest month and quarter is higher. Interestingly, preferences of American microplus for total precipitation show values three times higher than for other taxa analysed.

Figure 5 shows the cluster analysis as performed separately among the demes of each population. In this figure, each symbol corresponds to a record of the species, collected in one of the vegetation areas as separated by signature analysis of the NDVI monthly values. This kind of analysis provides information about the relative position within the space of ecological preferences, and the degree of ecological separation among the demes. The records of B. annulatus as well separated demes are easily appreciated, being the bottomright records those collected around Mediterranean zones. However, subSahelian records appear close to the rest of collections, meaning for similar preferences. Figure $5 \mathrm{~b}$ displays the relative position of records of both $B$. decoloratus and African B. microplus, considered as a whole without separation in demes. It is easily observed that the preferences of $B$. microplus lie almost in the middle of the space of preferences of $B$. decoloratus ticks. Furthermore, it is observed (Figure 5c) that demes within decoloratus constitute a very heterogeneous assemblage. Critical demes lying in the border of the statistically homogeneous envelope of the species are those labelled as 25 (portions of Ethiopia, Democratic Republic of Congo and Cameroon, see also Figure 1) and 18 (much of the western distribution range, see Figure 1). Specimens within the deme labelled as 15 have been dispersedly collected in Eastern Africa, in small transitional areas of undifferentiated woodland, Zambezian miombo and zones of mosaic of evergreen bush land and secondary Acacia grassland. It seems that the main factor separating this deme from the main ecological preferences of the species is the relatively high altitude of collections, which causes lower temperatures. Collections for B. geigyi specimens show a clear separation among the only 4 demes analysed (Figure $5 \mathrm{~d}$ ). Demes 15 and 16 (collected in the sub-Sahara zones, with lowest NDVI values) are close one to each other in their climate preferences, while deme 20 (recorded in most vegetated parts of western Africa) has obvious differences with the formers. Specimens in deme 18 lie in an intermediate position between the remaining demes. The collections of Latin American microplus are very homogeneous according to their climate preferences (Figure 5e) and only deme 47 (present in the North-central moist Andes) appears as separated from the remaining tightly grouped demes.

\section{Discussion}

This study presents the distribution and climate preferences of four boophilid tick species in Africa and Latin America, from a database of tick collections including more than 24,000 edited records. Therefore, it is the most extensive 

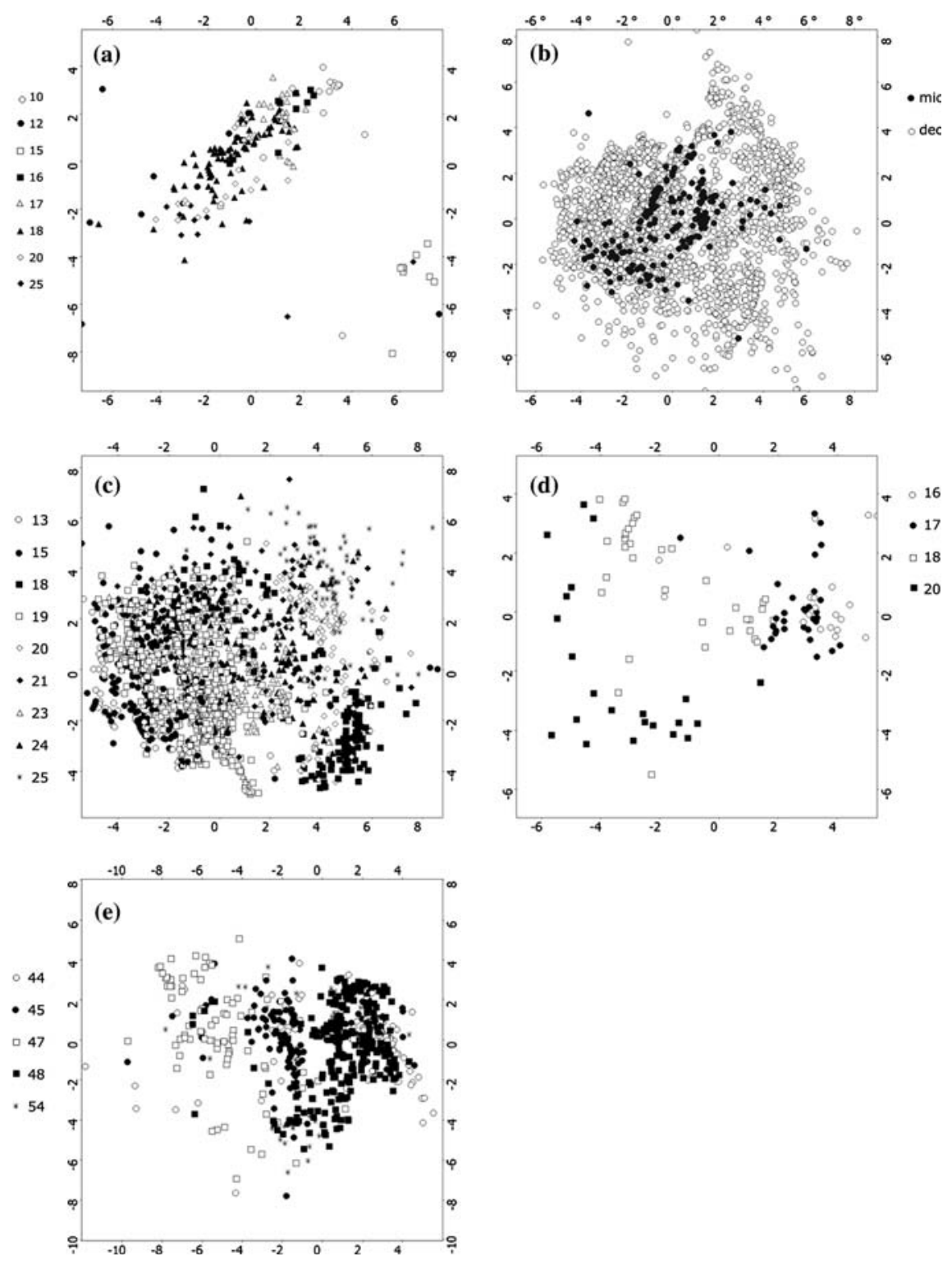

Figure 5. Cluster analysis of demes of Boophilus ticks, separated according to the classification of remotely sensed vegetation features (as displayed in Figures 1 to 3). Each symbol represents a deme, identified with a unique number, according to the vegetation category as displayed in previous figures. The charts show the coordinates in the factorial plane of the first two axes of the collections belonging to a given deme. (a) B. annulatus; (b) compared distribution of populations of African B. microplus (mic) and B. decoloratus (dec) without separation in demes; (c) B. decoloratus; (d) B. geigyi; (e) Latin American B. microplus. The analysis was not done separately for African records of $B$. microplus because the high dispersion of records. 
and updated registry of the distribution of these ticks within the regions considered. Much work remains to be done with records of B. microplus in Asia and the distribution of $B$. annulatus in the former soviet republics. References for these regions lack adequate spatial references (Morel 1965), and accession to the original collections to check the species determination is sometimes difficult.

Cluster analysis has been used in this paper to compare the climate preferences of the involved species, by assessing the $n$-dimensional space of the climate variables as occupied by each species. Hutchinson (1957) defined the fundamental ecological niche as comprising those environmental conditions within which a species can survive and grow: a conceptual space whose axes include all the environmental variables affecting that species. Unsupervised classification of monthly composites of the Normalized Difference Vegetation Index (NDVI) has been explored to further divide each continent into areas with ecological meaning. The classification produces a set of categories based on the seasonal dynamics of NDVI, enclosing regions that are homogeneous within each category and statistically different between them, providing a framework to compare the ecological preferences of the tick populations of each species (called herein demes) collected in the regions. NDVI is an estimation of the vegetation stress and is not linearly correlated with single climate variables (Rasmussen 1998). This procedure together with cluster analysis on demes has been able to show the existence of significant differences in the climate data recorded for the demes within the same species. There is increasing evidence that the concept of undifferentiated species comprising individuals with broad tolerances is not correct (Davis and Shaw 2001). Intra-species variation makes it impossible to define precise limits to the climatic tolerance of a species since there is no guarantee that the limits for one deme at one range margin will be exactly the same as those for another deme at another margin. Predictive modelling of species geographic distributions based on the environmental conditions of sites of known occurrence constitutes an important technique in analytical biology. In this context, a niche-based model represents an approximation of a species ecological niche in the examined environmental dimensions. In a study over a large region, spatial variation exists in the environmental conditions available to the species. It is expected that, for large regions and with the usual spatial variations in environmental conditions, differentiated populations of the target species may exist, occupying different steps within the fundamental niche of the species. These populations are obscured when niche-based models are applied to the whole area of the species distribution. Given that the prediction engines are feed with every available record, geographically projected results can be dangerously biased if populations are not recognized and modelled separately (Osborne and Suárez-Seoane 2002).

Both B. geigyi and B. annulatus have been collected in areas displaying highest temperatures, and high seasonal rainfall. The known African distribution of the two species lies within a narrow band extending into the 
parallels $10^{\circ}$ and $20^{\circ}$ N. B. geigyi is restricted to the warmer and more humid portions of western Africa, while B. annulatus extends further east. The later is also common in the Mediterranean basin. Both branches of the African B. annulatus distribution (Mediterranean and sub-Saharan) are clearly different according to cluster analysis, but these differences may be produced because the distinct seasonality in the climate recorded in both parts of the distribution range. Anyway, vegetation signatures are clearly different between these demes, those located in the Mediterranean and immediately south of Sahara having a low yearly NDVI, while those collected further south displaying high yearly NDVI values. Analysis of records of $B$. geigyi provides the separation into heterogeneous clusters, demes collected in central and south Mali clustering closely, and those recorded from the most western portions in Africa (around parallel $10^{\circ} \mathrm{W}$ ) into a different group. It is of interest to note that the vegetation areas to which geigyi is associated extend further into east Africa. The absence of the species from eastern portions of the Continent may be due to misidentifications or to the absence of adequate prospective work in the zones. Both annulatus and geigyi may appear together as they share the main signature of NDVI in western Africa. Nothing is known about the compared seasonal activity of both species in the zones where their distribution overlaps.

Boophilus decoloratus is widespread in sub-Saharan Africa. It is absent from deserts and in the most humid parts of central Africa. It is a species with requirements of low temperature and rainfall, being present at most altitude ranges and almost under rainfall zones, being most common in zones obtaining $500-1000 \mathrm{~mm}$ per year, surviving in zones with an annual rainfall as low as $380 \mathrm{~mm}$ (Walker et al. 1978). B. decoloratus can survive in areas where there is a maximum of 90 days of frost spread over a period of 150 days a year (Gothe 1967). At lower temperatures there may be pockets of suitable climatic conditions where it can survive (Theiler 1949). Cluster analysis suggests a relative homogeneity within the demes collected through the continent. Only the specimens collected at the northern part of its distribution range (associated with areas of high and almost seasonally invariable NDVI) show a certain degree of heterogeneity when compared with other demes of the species. The remaining zonesto which it is associated show the same pattern in NDVI: a period of high NDVI values between January and July, then a sudden decrease of this index. In areas of western Africa, decoloratus, annulatus and geigyi may appear associated, but there is a trend for B. decoloratus to be located in areas of lower temperature and rainfall.

There is a clear contrast between climate preferences recorded for B. microplus in both Africa and America concerning monthly maximum temperatures (higher in American collections), precipitation of driest and coldest quarters (three times higher in American records) and rainfall seasonality (very marked in African collections). However, it must to be realized that high rainfall in the African records has been recorded in the summer period. Therefore, although total rainfall preferences are higher in B. microplus than in $B$. decoloratus, the former may stand in areas with relatively long periods of 
dryness, probably synchronizing the cycle to avoid coincidence of critical phases with drought. Some references to the rainfall preferences of B. microplus in Africa points to high rainfall requirements, like the comments by Theiler (1962, "in all probabilities collected from well irrigated farms") Yeoman and Walker (1967, "must be considered a species of the high rainfall areas...from 400 to 1000 mm") and De Vos) 1979, "absent in areas where rainfall is less than $500 \mathrm{~mm}$ "). Seasonal rainfall changes supported by B. microplus have been reported as similar to those supported by $B$. decoloratus (Arthur and Londt 1973) as recorded in the current paper.

Cluster analysis between $B$. decoloratus and $B$. microplus shows that the African B. microplus are located within the $n$-dimensional ecological niche of demes of $B$. decoloratus. Therefore, the ecological preferences of African microplus cannot be extrapolated from those of American populations. In Africa, B. microplus had not invaded all areas that were climatically favourable for this species, as obtained by a modelling approach Sutherst and Maywald 1985). This failure was interpreted as being due to attempted interbreeding between $B$. microplus and $B$. decoloratus, resulting in a zone of sterile hybrids, which would present a barrier to further spread (Sutherst 1987). Several authors have discussed the mechanisms of the displacement of one species by the other. We think that previous models should be re-evaluated with the current knowledge of African B. microplus preferences. Anyway, there are large geographic areas at risk of colonization by $B$. microplus in Africa, if the tick should continue to spread from its present sites. The tick is common in parts of South Africa, Swaziland, Zimbabwe, where it was probably introduced from Mozambique in the mid-1970s (Norval et al. 1992) or Zambia, and already reported for other parts in Africa (Theiler 1962; McLeod and Mwanaumo 1978; Berkvens et al. 1998). The spread has been recently observed in Tanzania (Lynen, personal communication). Realistic simulations of the impact of climate on the spread of B. microplus in Africa will require a better understanding of the complex interactions between the many factors affecting distribution, including dynamic models to simulate the relationships between climate and the potential of the species to disperse through fragmented landscapes, and the relations between $B$. microplus and $B$. decoloratus on host.

The primary purpose of this study should then be regarded as an attempt to provide an accurate ecological basis in the building of predictive models of tick distribution under current and future climate conditions in the considered regions. Modelling strategies for predicting potential distributions of ticks have focused on the characterization of the bioclimate envelope (Cumming 2002; Olwoch et al. 2003; Estrada-Peña 2003). Some recent studies have questioned the validity of this approach by pointing to the many factors other than climate that play an important part in determining species distributions (Davies et al. 1998; Lawton, 2000). Concerning ticks, both dispersal ability by hosts and vegetation may have potential impact in the predictive mapping. However Pearson and Dawson (2003) concluded that the bioclimate envelope approach could provide a useful first approximation, stressing also the importance of the 
spatial scale. The limit of the scale in our work and the accuracy of some records imposed a restriction to additional studies on associations with the vegetation. Cumming (2002) proposed that continental-scale distributions of ticks are principally determined by climate, and it is therefore suggested that many species distributions can in fact be considered to be in equilibrium with the current climate at the macro-scale. Genetic adaptation of species is rarely considered, being range shifts frequently seen as the expected response to the climate. It is usually expected that evolutionary change occurs only on long time scales and that the tolerance range of a species remains the same as it shifts its geographical range (Pearson and Dawson 2003). However, studies have shown that climate-induced range shifts can involve not only migration into newly suitable areas, but also selection against phenotypes that are poorly adapted to local conditions (Davis and Shaw 2001). The finding of Boophilus populations with statistically different climate preferences should be regarded as an additional problem in understand and map the climate factors responsible for tick distribution. Of particular importance is the divergence of African and American B. microplus populations and the apparent difficulty to capture the evolving ecological plasticity of tick populations.

\section{Acknowledgements}

The authors want to thank the collaboration of E. Foka, University of Buea, Cameroon, and F. Stachurski, CIRAD-EMVT, CIRDES, Burkina Fasso, by the comments about the distribution of Boophilus ticks in western Africa. This work has been facilitated by the The Integrated Consortium on Ticks and Tick-borne Diseases (ICTTD-3), financed by the International Cooperation Program of the European Union through Coordination Action Project no. 510561.

\section{References}

Arthur D.R. and Londt J.G.H. 1973. The parasitic cycle of Boophilus decoloratus (Koch 1844) (Acarina: Ixodidae). J. Ent. Soc. Southern Africa 36: 87-116.

Beati I. and Keirans J.E. 2001. Analysis of the systematic relationships among ticks of the genera Rhipicephalus and Boophilus (AcarI: Ixodidae) based on mitochondrial 12S ribosomal DNA gene sequences and morphological characters. J. Parasitol. 87: 32-48.

Berkvens D.L., Geysen D.M., Chaka G., Madder M. and Brandt J.R.A. 1998. A survey of the ixodid ticks parasitizing cattle in the Eastern province of Zambia. Med. Vet. Entomol. 12: 234-240.

Cumming G.S. 1999. The Evolutionary Ecology in African Ticks (Acari: Ixodidae). PhD Thesis, University of Oxford, Oxford, UK.

Cumming G.S. 2002. Comparing climate and vegetation as limiting factors for species ranges of African ticks. Ecology 83: 255-268.

Davies A.J., Jenkinson L.S., Lawton J.L., Shorrocks B. and Wood S. 1998. Making mistakes when predicting shifts in species range in response to global warming. Nature 391: 783-786. 
Davis M.B. and Shaw R.G. 2001. Range shifts and adaptive responses to Quaternary climate change. Science 292: 673-679.

De Vos A.J. 1979. Epidemiology and control of bovine babesiosis in South Africa. J. South African Vet. Assoc. 50: 357-362.

Estrada-Peña A. 2003. Climate change decreases habitat suitability for some tick species (Acari: Ixodidae) in South Africa. Onderstepoort J. Vet. Res. 70: 79-93.

George J.E. 1987. Cattle fever tick eradication programme in the USA: history, achievements, problems and implications for other countries. In "The eradication of ticks", Proceedings of the expert consultation on the eradication of ticks with special reference to Latin America, pp. 1-7

Gothe R. 1967. Ticks in the South African Zoological Survey Collection. Part XII. The genera Boophilus Curtice, 1891 and Margaropus Karsch, 1879. Onderstepoort J. Vet. Res. 38: 81-108.

Holt R.D. 1996. Adaptive evolution in source-sink environments: direct and indirect effects of density-dependence on niche evolution. Oikos 75: 182-192.

Holt R.D. and Gomulkiewicz R. 1996. The evolution of species niches: population dynamics perspectives. In: Othmer H.G. (eds), Case Studies in Mathematical Modelling: Ecology, Physiology, and Cell Biology. Prentice Hall, Saddle River, New Jersey, USA, pp. 1-7

Horak I.G., Camicas J.-L. and Keirans J.E. 2002. The Argasidae, Ixodidae and Nuttalliellidae (Acari: Ixodida): a list of valid tick names. Exp. Appl. Acarol. 28: 27-54.

Hutchinson G.E. 1957. Concluding remarks. In "Population studies: animal ecology and demography". Cold Spring Harbor Symposia on Quantitative Biology, vol. 22. Cold Spring Harbor Laboratory Press.

International Consortium of Ticks and Tick-Borne Diseases (ICTTD) 2004. Ticks of Veterinary and Medical Importance. A series of three CD's on ticks on livestock in Afruca, the Mediterranean Region and Latin America (http://www.icttd.nl).

Lawton J.L. 2000. Concluding remarks: a review of some open questions. In: Hutchings M.J., John E. and Stewart A.J.A. (eds.), Ecological Consequences of Heterogeneity. Cambridge University Press, Cambridge, pp. 401-424.

McLeod J. and Mwanaumo B. 1978. Ecological studies of ixodid ticks (Acari: Ixodidae) on cattle in Zambia. IV: Some anomalous infestation patterns in the northern and eastern regions. Bull. Entomol. Res. 68: 409-429.

Morel P.-C. 1965. Les tiques de l'Afrique et du Bassin Méditerranéen (Ixodoidea). Unpublished manuscript. IEMVPT, Maisons-Alfort, France, pp. 1105

Murrell A.N., Campbell J.H. and Barrer S.C. 2000. Phylogenetic análisis of the rhipicephaline ticks indicates that the genus Rhipicephalus is paraphyletic. Mol. Phylogenet. Evol. 16: 1-7.

New M., Hulme M. and Jones P.D. 1999. Representing twentieth century space-time climate variability. Part I. development of a 1950-1999 mean monthly terrestrial climatology. J. Climate 12: 829-56.

Norval R.A.I., Perry B.D. and Hargreaves S.K. 1992. Tick and tick-borne disease control in Zimbabwe: what might the future hold? Zimbabwe Vet. Journal 23: 1-15.

Olwoch J.M., Rautenbach C.J. de W., Erasmus B.F.N., Engelbrecht B.F.A. and Jaarsveld A.S. 2003. Simulating tick distributions over sub-Saharan Africa: the use of observed and simulated climate surfaces. J. Biogeography 30: 1221-1232.

Osborne P. and Suárez-Seoane S. 2002. Should data be partitioned before building large distribution models? Ecol. Modelling 157: 249-259.

Pearson R.G. and Dawson T.P. 2003. Predicting the impacts of climate change on the distribution of species: are bioclimate envelope models useful? Global Ecol. Biogeography 12: 361-371.

Rasmussen M.S. 1998. Developing simple, operational, consistent NDVI-vegetation models by applying environmental and climatic information. Part I: Assessment of net primary production. Int. J. Remote Sensing 19: 97-117.

Robinson T.P. 1998. Geographic information systems and the selection of priority areas for control of tsetse-transmitted trypanosomiasis in Africa. Parasitology Today 14: 457-461.

Sutherst R.W. 1987. The dynamics of hybrid zones between tick (Acari) species. Int. J. Parasitol. 17: 921-926. 
Sutherst R.W. and Maywald G.F. 1985. A computerised system for matching climates in ecology. Agric. Ecosyst. Environ. 13: 281-299.

Theiler G. 1949. Zoological survey of the Union of South Africa: Tick survey. Part II: Distribution of Boophilus(Palpoboophilus) decoloratus, the blue tick. Onderstepoort J. Vet. Sci. Animal Industry 22: 255-268.

Theiler G. 1962. The Ixodidae parasites of vertebrates in Africa south of the Sahara. Project S 9958. Report to the Director of Veterinary Services, Onderstepoort, South Africa.

Tonnesen M.H., Penzhorn B.L., Bryson N.R., Stoltsz W.H. and Masiwigiri T. 2004. Displacement of Boophilus decoloratus by Boophilus microplus in the Soutpansberg region, Limpopo province, South Africa. Exp. Appl. Acarol. 32: 199-208.

Walker J.B., Mehlitz D. and Jones G.E. 1978. Genus Boophilus: The Blue Ticks. Notes on the Ticks of Botswana. GTZ, Eschborn, pp. 30-35

Walker A.R., Bouattour A., Camicas J.-L., Estrada-Peña A., Horak I., Latif A., Pegram R. and Preston P. 2003. Ticks of Domestic Animals in Africa. A Guide to Identification of Species. University of Edinburgh, $221 \mathrm{pp}$.

Yeoman G.H. and Walker J.B. 1967. The ixodid ticks of Tanzania. Commonwealth Institute of Entomology, London. 